\title{
SINTOMAS CLÍNICOS DE PACIENTES RECUPERADOS DA COVID-19 EM REGIÕES DA AMAZÔNIA ORIENTAL
}

\section{ARTIGO ORIGINAL}

OLIVEIRA, Edith Cibelle de ${ }^{1}$

QUEIROZ, Cleonilde ${ }^{2}$

MOREIRA, Paulo Eliezer de Oliveira ${ }^{3}$

PINHEIRO, Luiz Marcelo de Lima ${ }^{4}$

CUNHA, Divino Bruno da ${ }^{5}$

OLIVEIRA, Edith Cibelle de. Et al. Sintomas clínicos de pacientes recuperados da COVID-19 em regiões da Amazônia Oriental. Revista Científica Multidisciplinar Núcleo do Conhecimento. Ano 05, Ed. 11, Vol. 04, pp. 57-65. Novembro de 2020.

${ }^{1}$ Doutorado em Genética e Biologia Molecular. Mestrado em Genética e Biologia Molecular. Graduação em Ciências Biológicas.

2 Doutorado em Programa de Pós-Graduação em Biologia Ambiental. Mestrado em Genética e Biologia Molecular. Graduação em Ciências Biológicas.

${ }^{3}$ Mestrado em Odontologia. Especialização em Saúde da Família. Especialização em ortodontia. Graduação em odontologia.

${ }^{4}$ Doutorado em Biologia de Agentes Infecciosos e Parasitários. Mestrado em Genética e Biologia Molecular. Especialização em Sistemática e Evolução Molecular. Graduação em Ciências Biológicas Modalidade Licenciatura. Graduação em Ciências Biológicas Modalidade Bacharelado.

${ }^{5}$ Doutorado em Programa de Pós-graduação em Biologia Ambiental. Mestrado em Genética e Biologia Molecular. Graduação em Licenciatura Plena em Ciências Biológicas. 
ISSN:

2448-0959,

Link

de

acesso: https://www.nucleodoconhecimento.com.br/saude/amazonia-oriental

\section{RESUMO}

A pandemia causada pelo novo coronavírus (COVID-19) já provocou a morte de mais 142 mil pessoas no Brasil, levando alguns Estados a decretarem colapso do sistema de saúde. A COVID-19 é uma doença de perfil sintomatológico variável, com espectro altamente diverso. No Brasil a grande maioria da população não tem acesso a testes diagnósticos para COVID-19 e estudar os sintomas clínicos se torna relevante para identificar possíveis disseminadores do vírus. Assim, o presente estudo teve como objetivo descrever os sintomas clínicos mais prevalentes em pacientes recuperados de COVID-19 em regiões da Amazônia oriental Brasileira. Para isso, foram aplicados questionários à pacientes testados positivo para Sars-Cov 2 afim de analisar os sintomas durante a infecção. Um total de 85 indivíduos participaram da pesquisa. Os sintomas observados em mais de $50 \%$ dos entrevistados foram febre, tosse, perda de olfato, rinite, dor de garganta, perda do paladar, dor na cabeça, dor nas articulações, dor na coluna, dor nas costas e dores musculares. Alguns dos pacientes após um curto período tornaram-se assintomáticos. Vale ressaltar que a compreensão exata dos sintomas clínicos da doença é de extrema importância, uma vez que a ampla variação observada faz com que o diagnóstico da COVID-19 seja complexo e desafiador.

Palavras-chave: Sintomas, clínicos, COVID-19, recuperados, Coronavírus.

\section{INTRODUÇÃO}

A pandemia causada pelo novo coronavírus (COVID-19) tem provocado inúmeras mortes ao redor do planeta (WHO, 2020). No mês de setembro do corrente ano, o Brasil registrou cerca de 4.745.464 mil casos de COVID-19, 142 mil óbitos e 4.084.182 pessoas recuperadas, com taxa de letalidade em 67\% (WHO, 2020; BRASIL, 2020) 
A velocidade de disseminação do vírus no Brasil tem ocorrido de forma rápida, levando alguns estados, como Pará, Amazonas e Amapá, a decretarem colapso total do sistema de saúde. No estado do Pará, o número de casos confirmados para COVID19 já ultrapassou 230.449 mil, com 6.573 casos de óbitos e 214.272 pessoas recuperadas (BRASIL, 2020). A região Norte apresenta alto índice de carência de médicos, leitos de UTI, respiradores e realização de testes diagnósticos, tornando cenário ainda mais preocupante.

Diante do caótico quadro que assola a humanidade, a Organização Mundial de Saúde (WHO, 2020) tem adotado algumas ações paliativas para mitigar o contágio pandêmico. As principais ações são distanciamento social e prevenção primária, uma vez que não existe remédio antiviral para tratar a COVID-19 e tampouco vacina. Essas ações estão sendo adotadas globalmente na tentativa de achatamento da curva de contágio e, como tentativa de evitar o colapso do sistema de saúde. Segundo o Instituto Nacional de Saúde (NIH) dos EUA, a melhor forma de prevenir a COVID-19 é evitar a exposição ao vírus, pois este se espalha de pessoa a pessoa, a partir de gotículas respiratórias e salivares produzidas quando a pessoa infectada tosse, espirra ou fala (NIH, 2020). Se estas gotículas entrarem em contato com o nariz, boca ou olhos, as partículas virais poderão chegar aos pulmões.

A COVID-19 é uma doença de perfil sintomatológico bastante variável, pois apresenta um espectro altamente diverso. Alguns indivíduos infectados podem ser totalmente assintomáticos, enquanto outros evoluem para quadros de infecções respiratórias extremamente graves e, por vezes, fatais (LI et al., 2020). Estudos sugerem que a COVID-19 pode ser transmitida por infectados assintomáticos (NIH, 2020). Quando os sintomas são manifestados no indivíduo infectado, eles variam de um simples resfriado leve, passando por febre, tosse seca, dores de cabeça e garganta, cansaço físico, diarreia, complicações respiratórias agudas graves, pneumonia, perda de olfato e do paladar (LI et al., 2020). No entanto, a infecção humana causada pelo novo coronavírus (2019-nCoV), no que diz respeito ao espectro clínico, não está bem descrita. Logo, não se sabe o seu padrão de letalidade, mortalidade, infectividade e transmissibilidade (CUI et al., 2019). 
Poucos estudos têm sido conduzidos em regiões negligenciadas no Brasil. Desta maneira, o objetivo deste é descrever a sintomatologia clínica mais prevalente em pacientes potencialmente recuperados de COVID-19 em regiões da Amazônia Oriental Brasileira.

\section{METODOLOGIA}

Esta pesquisa foi submetida ao comitê de ética em pesquisa com seres humanos, tendo um termo de consentimento livre e esclarecido (TCLE) assinado por todos os envolvidos. Trata-se de um estudo observacional, descritivo e retrospectivo.

Os indivíduos foram selecionados preenchendo o seguinte critério de inclusão: pacientes testados positivamente para COVID-19, potencialmente recuperados para a COVID-19 e residentes em cidades da Amazônia brasileira (Bragança, Capanema, Marabá, Cidades do Arquipélago do Marajó, Belém e Região Metropolitana).

Um questionário foi aplicado, via Microsoft Forms, para analisar a sintomatologia durante a infecção por Sars-Cov-2.

Após a coleta, os dados foram tabulados utilizando o programa Microsof Excel $2013^{\circledR}$ (Microsoft, Redmond, WA, USA). Para a realização da análise estatística descritiva, as variáveis categóricas foram fornecidas por meio de frequências e porcentagens.

O estudo foi aprovado pelo em Comitê de Ética em pesquisa da Universidade Federal do Pará sob o número 4.071.811.

\section{RESULTADOS E DISCUSSÃO}

Oitenta e cinco (85) pacientes potencialmente recuperados de COVID-19 responderam ao questionário. Dentre eles, 3,6\% com idade entre 11-20 anos, 21,7\% com idade entre $21-30$ anos, $33,7 \%$ com idade entre 31 e 40 anos, $24,1 \%$ com idade entre 41 e 50 anos e $3,6 \%$ com mais de 60 anos, conforme mostra a figura 1 . 
Figura 1: Quantitativo de indivíduos recuperados de COVID-19.

\section{Porcentagem de Idade dos entrevistados}

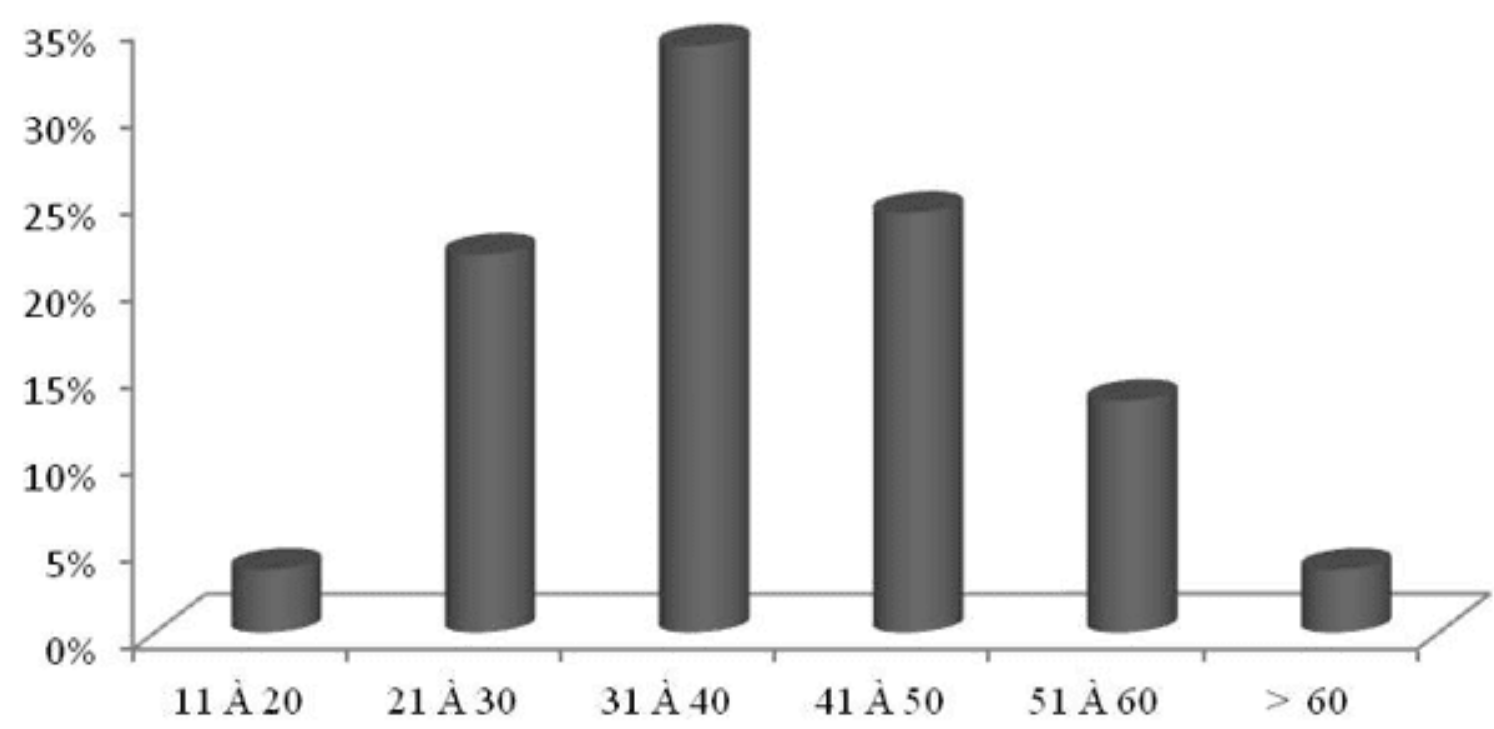

Fonte: O autor, 2020.

Os sintomas relatados pelos pacientes estão sumarizados na figura 2. De forma geral, 12 sintomas apareceram em mais de $50 \%$ dos entrevistados, dentre eles, febre, tosse, perda de olfato, rinite, dor de garganta, perda do paladar, dor na cabeça, dor nas articulações, dor na coluna, dor nas costas e dores musculares.

Dentre os sintomas relacionados às doenças que acometem o trato respiratório, $67,5 \%$ apresentaram tosse, destes, 46,4\% relataram uma intensidade moderada do sintoma, variando entre seca (86\%), e com secreção (14\%). A grande maioria dos pacientes entrevistados relatou ainda perda de olfato $(67,5 \%)$ e falta de ar $(42,2 \%)$. Porém, outros sintomas, como dor no pulmão $(37,3 \%)$, rinite $(48,8 \%)$ e dor na garganta $(63,9 \%)$ também foram observados. 
Figura 2: Principais sintomas relatados pelos indivíduos recuperados de COVID-19.

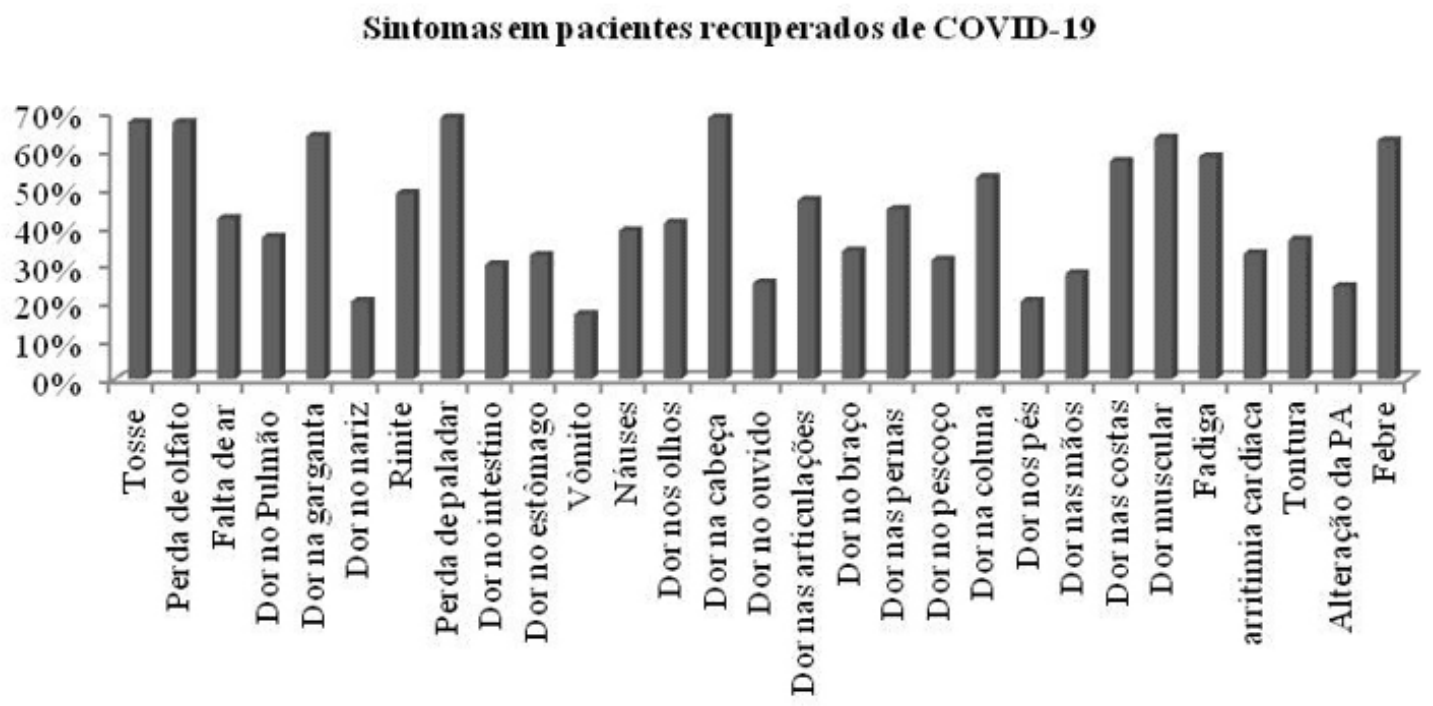

Fonte: O autor, 2020.

Nossos resultados estão de acordo com os dados da literatura científica, que mostram que a tosse seca, dor na garganta e falta de ar são sintomas prevalentes em pacientes acometidos por COVID-19 (SCHMULSON et al., 2020), assim como a dor de garganta, observada em vários pacientes hospitalizados (LOVATO et al., 2020). Por outro lado, a perda de olfato (anosmia), observada em grande parte de pacientes em áreas emergentes da Amazônia, também tem sido reportada na Europa como um sintoma característico em pacientes com COVID-19 leve à moderada (LECHIEN et al., 2020). A sintomatologia mais expressiva relacionada ao trato digestivo, observada durante 0 período da doença, inclui perda no paladar em aproximadamente $68 \%$ dos casos, e náuseas em 39\%. Outros sintomas observados foram dor no estômago $(32,5 \%)$, intestino $(30,1 \%)$ e vômito $(17,1 \%)$.

A perda de paladar (ageusia), tal como anosmia, tem sido frequentemente relatada em pacientes infectados por COVID-19, uma vez que os tecidos da mucosa oral e nasal possivelmente contêm células que facilitam a entrada de SARS-CoV-2 (GIACOMELLI et al., 2020; HJELMESÆTHH et al., 2020). 
As manifestações gastrointestinais, observadas em alguns pacientes da Amazônia, ocorreram em menor porcentagem, ratificando os dados da literatura. De acordo com Schmulson (2020), a frequência de sintomas gastrointestinais, apesar de pouco recorrente, pode ser observada na progressão da COVID-19. Na Europa, esses sintomas foram relativamente baixos, enquanto na China se apresentarem em maior porcentagem. Tal como em nossos resultados, na China o sintoma mais recorrente observado foi náuseas.

A frequência dos sintomas relacionados a dores na região da cabeça e pescoço foram: dores de cabeça (68\%), dores nos olhos (41\%), no ouvido $(25,3 \%)$ e pescoço $(31,3 \%)$. Muitos estudos médicos têm registrado, em pacientes infectados pela COVID-19, dores na cabeça, mialgia e mal-estar, os quais podem ser manifestações inespecíficas causadas pela COVID-19 (WANG et al., 2020). Contudo, em um estudo envolvendo 214 pacientes com COVID-19, 78 (36,4\%) apresentaram manifestações neurológicas, como cefaleia, tontura, doença cerebrovascular e consciência prejudicada.

Os dados do presente trabalho estão de acordo a literatura científica e mostram que o sintoma dor de cabeça é prevalente nas pessoas com COVID-19. Além disso, um relatório descrito recentemente, no hospital de Beijing, confirma que o novo coronavírus pode atacar e danificar o sistema nervoso, comprovado pela detecção do RNA da SARS-CoV-2 no líquido cefalorraquidiano de um indivíduo (XINHUA, 2020). No estudo de Yeh (2004), os autores também detectaram sequências de RNA do novo coronavírus no líquido cefalorraquidiano de uma criança de 15 anos com encefalomielite.

Segundo Wang (2020), os sintomas mais comuns de pessoas infectadas com COVID19 são febre, tosse e fadiga. Além disso, estes mesmos autores afirmam que os pacientes ainda podem apresentar diarreia e náusea alguns dias antes da febre, sugerindo que esta é preponderante, mas não é o principal sintoma da infecção. No entanto, no presente estudo, foram relatados pelos pacientes potencialmente curados alguns sintomas expressivos, que incluem: fadiga excessiva $(58,5 \%)$ e febre $(62,7 \%)$. Estes achados são corroborados por estudos anteriores, que podem auxiliar para um diagnóstico mais completo da doença em pacientes assintomáticos e sintomáticos. 
A mialgia e a fadiga são sintomas registrados em vários estudos clínicos, assim como as anormalidades na tomografia do tórax do pulmão (TC) (WANG et al., 2020; GUAN et al., 2020). Contudo, boa parte dos pacientes relataram outros sintomas manifestados, como dores musculares (63,4\%), nas costas (57,3\%), nas articulações de braços $(44,6 \%)$ e pernas $(47 \%)$, nos membros superiores (braços $(33,7 \%)$, mãos $(27,7 \%)$ e nos membros inferiores, pernas $(44,6 \%)$ e pés $(20,5 \%)$. Vale lembrar que a compreensão exata dos sintomas clínicos da COVID-19 é de extrema importância. Contudo, as manifestações clínicas ainda são muito inespecíficas, e a doença pode evoluir de forma rápida para uma disfunção orgânica, como síndrome do desconforto respiratório agudo, lesão cardíaca, lesão renal aguda e até mesmo à morte, em casos graves (WANG et al., 2020; GUAN et al., 2020; MAO et al., 2020)

Em relação ao tempo de recuperação de pacientes, Pan (2020) analisou tomografias do tórax (TC) associadas ao COVID-19, desde o diagnóstico inicial até a recuperação, totalizando 26 pacientes. Tais autores observaram que os sinais de melhora no peito e a TC começaram, aproximadamente, 14 dias após o início dos sintomas iniciais. No presente estudo, o tempo de recuperação ocorreu em, aproximadamente, 13 dias após o início dos sintomas.

Contudo, foram registrados 02 pacientes que manifestaram dor na garganta, tosse seca e dor de cabeça durante um período de somente 72 horas (03 dias). Após este período, já se encontravam completamente sem sintomas. Por outro lado, foram registrados pacientes com prevalência dos sintomas até 28 dia após a exposição ao vírus.

É importante ressaltar que os 85 pacientes abordados neste estudo manifestaram de sintomas leves a moderados da doença. Cinco pessoas, após um curto período de tempo, tornaram-se assintomáticas, já a maioria dos pacientes levaram mais tempo para os sintomas desaparecerem, sendo que $32 \%$ dos indivíduos não apresentaram dores na cabeça, e 37,3\% não tiveram febre. 


\section{CONCLUSÃO}

No presente estudo evidenciou-se o perfil dos pacientes recuperados da COVID-19 nos municípios do estado Pará. Toda a variação observada na expressão da sintomatologia torna o delineamento do diagnóstico de COVID-19 muito mais complexa e desafiadora, o que potencialmente pode levar a diagnósticos errados, sendo que tais erros podem aumentar as taxas de transmissão da infecção, pois indivíduos assintomáticos continuam disseminando o vírus.

\section{REFERÊNCIAS BIBLIOGRÁFICAS}

BRASIL. Ministério da Saúde. Disponível em: <https://covid.saude.gov.br/>. Acessado em: 26/09/2020.

$\mathrm{CUI}, \mathrm{J}$; LI, F; SHI, ZL. Origin and evolution of pathogenic coronaviruses. Nat Rev Microbiol. 2019; 17(3):181-192. Disponível em: https://www.nature.com/articles/s41579-018-0118-9. Acessado em: 20/08/2020.

GIACOMELLI, A; PEZZATI, L; CONTI, F; BERNACCHIA, D; SIANO, M; ORENI, L, et al. Self-reported Olfactory and Taste Disorders in Patients With Severe Acute Respiratory Coronavirus 2 Infection: A Cross-sectional Study. Clin Infect Dis. 2020. Disponível em: https://pubmed.ncbi.nlm.nih.gov/32215618/. Acessado em: $10 / 09 / 2020$

GUAN, WJ; NI, ZY; HU, Y; LIANG, WH; OU, CQ; HE, JX, et al. Clinical Characteristics of Coronavirus Disease 2019 in China. N Engl J Med. 2020; 382:1708-20. Disponível em: https://www.nejm.org/doi/full/10.1056/NEJMoa2002032. Acessado em: 27/08/2020.

HJELMESÆTH, J; SKAARE, D. Covid-19 med nedsatt lukte- og smakssans som eneste symptom. Tidsskr Den Nor legeforening. 2020; 140(7)05-05. Disponível em: https://tidsskriftet.no/2020/04/kort-kasuistikk/covid-19-med-nedsatt-lukte-ogsmakssans-som-eneste-symptom. Acessado em: 10/09/2020. 
LECHIEN, JR; CHIESA-ESTOMBA, CM; DE SIATI, DR; HOROI, M; LE BON, SD; RODRIGUEZ, $A$, et al. Olfactory and gustatory dysfunctions as a clinical presentation of mild-to-moderate forms of the coronavirus disease (COVID-19): a multicenter European study. Eur Arc Oto-Rhino-Laryngology. 2020. Disponível em: https://link.springer.com/article/10.1007\%2Fs00405-020-06024-5. Acessado em: 10/09/2020.

LI, YC; BAI, WZ; HASHIKAWA, T. The neuroinvasive potential of SARS-CoV2 may play a role in the respiratory failure of COVID-19 patients. J Med Virol. 2020; 92:552-555. Disponível em: https://www.ncbi.nlm.nih.gov/pmc/articles/PMC7228394/. Acessado em: 20/08/2020.

LOVATO, A; ROSSETTINI, G; DE FILIPPIS, C. Sore throat in COVID-19: Comment on "Clinical characteristics of hospitalized patients with SARS-CoV-2 infection: A single arm meta-analysis. J Med Virol. 2020; 1-2. Disponível em: https://pubmed.ncbi.nlm.nih.gov/32239511/. Acessado em: 23/07/2020.

MAO, L; JIN, H; WANG, M; HU, Y; CHEN, S; HE, Q, et al. Neurologic Manifestations of Hospitalized Patients With Coronavirus Disease 2019 in Wuhan, China. JAMA Neurol. 2020; 20:11-27.

Disponível

em: https://jamanetwork.com/journals/jamaneurology/article-abstract/2764549. Acessado em: 12/08/2020.

NATIONAL INSTITUTES OF HEALTH - NIH. Disponível em: <https://www. nih. gov/health-information/coronavirus>. Acessado em: 20/08/2020.

PAN, F; YE, T; SUN, P; GUI, S; LIANG, B; LI, L, et al. Time Course of Lung Changes at Chest CT during Recovery from Coronavirus Disease 2019 (COVID-19). Radiology. 2020; 295(3): 715-721. Disponível em: https://www.ncbi.nlm.nih.gov/pmc/articles/PMC7233367/. Acessado em: 15/09/2020.

SCHMULSON, M; DÁVALOS, MF; BERUMEN, J. Alerta: los síntomas gastrointestinales podrían ser una manifestación de la COVID-19. Rev Gastroenterol México. 2020; Disponível em: 
http://www.revistagastroenterologiamexico.org/es-pdf-S0375090620300446. Acessado em: 20/06/2020.

WANG, Y; WANG, Y; CHEN, Y; QIN, Q. Unique epidemiological and clinical features of the emerging 2019 novel coronavirus pneumonia (COVID-19) implicate special control measures. J Med Virol. 2020; 92:568-576. Disponível em: https://onlinelibrary.wiley.com/doi/full/10.1002/jmv.25748. Acessado em: 10/08/2020.

WORLD HEALTH ORGANIZATION - WHO. W-CJM On CD 2019 (COVID-19). Disponível em: <https://www.who.int/emergencies/diseases/novel-coronavirus2019?gclid=EAlalQobChMI-

_PljuKa6gIVCweRCh3VpwANEAAYASAAEgL4iPD_BwE>. Acessado em: 26/09/2020.

XINHUA. Beijing hospital confirms nervous system infections by novel coronavirus. Disponível em: http://www.xinhuanet.com/english/202003/05/c_138846529. Acessado em: 25/08/2020.

YEH, EA; COLLINS, A; COHEN, ME; DUFFNER, PK; FADEN, H. Detection of coronavirus in the central nervous system of a child with acute disseminated encephalomyelitis. Pediatric. 2004. 113(1)73-75. Disponível em: https://pediatrics.aappublications.org/content/113/1/e73.long. Acessado em: 25/08/2020.

Enviado: Outubro, 2020.

Aprovado: Novembro, 2020. 